\title{
O cuidado de enfermagem ao neonato pré-termo em unidade neonatal: perspectiva de profissionais de enfermagem
}

Nursing care of preterm newborns in a neonatal unit: the perspective of nursing professionals

Cuidado de enfermería al neonato prematuro en unidad neonatal: perspectiva de profesionales de enfermería

Loiana Gomes Silva ${ }^{1}$, Rosália Teixeira de Araújo², Marizete Argolo Teixeira³

\section{RESUMO}

A prematuridade põe em risco a vida de neonatos pela imaturidade morfológica e funcional de seus órgãos. Objetivou-se com este estudo analisar a práxis cuidativa da equipe de enfermagem de uma Unidade Neonatal ao neonato pré-termo. Trata-se de estudo de natureza qualitativa, desenvolvido na Unidade Neonatal de um hospital público em Jequié-BA com onze profissionais da equipe de enfermagem. Utilizou-se entrevista semiestruturada para coleta de dados, estes foram analisados por meio da técnica de análise de conteúdo temática. Os resultados revelaram que os profissionais de enfermagem focam suas práticas cuidativas ao neonato pré-termo com predominância nos aspectos biológicos, embora valorizem os aspectos subjetivos que envolvem o cuidado de enfermagem. Dessa maneira, faz-se necessário a implantação das normas de humanização de cuidado aos neonatos pré-termo de modo que os profissionais de enfermagem possam incorporar na íntegra os seus pressupostos.

Descritores: Cuidado de Enfermagem; Prematuro; Neonatologia.

\section{ABSTRACT}

Prematurity puts newborns at risk due to the morphologic and functional immaturity of their organs. The objective of this study was to analyze the care provided to preterm infants by the nursing team of a neonatal unit. This qualitative study was performed at the Neonatal Unit of a public hospital in Jequié (Bahia) with eleven professionals of the nursing team. Data were collected using semi-structured interviews and were subsequently submitted to thematic content analysis. Results showed that nursing professionals focus the care provided to preterm newborns mainly on biological aspects, although they value the subjective aspects involving nursing care. Therefore, it is necessary to implement norms for the humanization of care provided to preterm newborns so that nursing professionals may fully incorporate those principles.

Descriptores: Nursing Care; Infant, Premature; Neonatology.

\section{RESUMEN}

La prematuridad pone en riesgo la vida de neonatos por inmadurez morfológica y funcional de sus órganos. Se objetivó analizar la práctica de cuidados del equipo de enfermería de una Unidad Neonatal al neonato prematuro. Estudio cualitativo desarrollado en Unidad Neonatal de hospital público en Jequié-Bahia, con 11 profesionales del equipo de enfermería. Se utilizó cuestionario semiestructurado para recolección de datos, los cuales fueron analizados mediante técnica de análisis de contenido temático. Los resultados expresaron que los profesionales de enfermería enfocan sus prácticas de atención al neonato prematuro con predominio en los aspectos biológicos, aunque también valorizan los aspectos subjetivos que involucra la atención de enfermería. Siendo así, resulta necesaria la implantación de normas de humanización del cuidado a neonatos prematuros, de manera tal que los profesionales de enfermería puedan incorporar sus presupuestos en forma integral.

Descriptors: Atención de Enfermería; Prematuro; Neonatología.

\footnotetext{
'Trabalho de Conclusão de Curso apresentado ao Curso de Graduação em Enfermagem da Universidade Estadual do Sudoeste da Bahia (UESB).

${ }^{1}$ Enfermeira. Jéquie, BA, Brasil. E-mail: loyanagomes@gmail.com.

${ }^{2}$ Enfermeira, Mestre em Enfermagem. Professora Assistente da UESB. Jéquie, BA, Brasil. E-mail: rosluz@gmail.com.

${ }^{3}$ Enfermeira, Doutora em Enfermagem. Professora Assistente da UESB. Jéquie, BA, Brasil. E-mail: loyanagomes@hotmail.com.
} 


\section{INTRODUÇÃO}

Anualmente, em torno de 20 milhões de neonatos nascem com baixo peso em consequência de um nascimento prematuro ou retardo do crescimento intrauterino, a maioria dessas crianças nasce em países subdesenvolvidos(1).

O nascimento prematuro é uma agressão ao feto, uma vez que, em sua última etapa intra-uterina, ele apresenta órgãos em fase de desenvolvimento, com imaturidade morfológica e funcional(2). Por conseguinte, está associado as altas taxas de morbimortalidade em menores de um ano(1).

No Brasil, a primeira causa de mortalidade infantil são as afecções perinatais, que compreendem os problemas respiratórios, a asfixia ao nascer e as infecções, mais comuns em neonato pré-termo e de baixo peso. Além disso, muitos neonatos são acometidos por distúrbios metabólicos, dificuldades para alimentarse e para regular a temperatura corporal(3).

Os avanços científicos na área da neonatologia tem garantido a sobrevivência de crianças prematuras, que há algumas décadas, eram consideradas inviáveis pela ciência, em contrapartida, tem-se os elevados custos para os sistemas de saúde e seguridade social no mundo. Muito embora nos países subdesenvolvidos deparamonos com escassez de recursos tecnológicos e humanos qualificados para atender essa clientela(1).

A Unidade Neonatal é o local onde o neonato prétermo é hospitalizado ficando na incubadora por um período suficiente para se recuperar do parto e estabilizar seus parâmetros como: peso, temperatura, respiração e frequência cardíaca. É nesse mesmo ambiente que o neonato também vivencia sentimentos de desamparo, pois, com a separação brusca da mãe, ele será privado de tudo o que um neonato nascido a termo recebe, não terá os cuidados maternos e paternos, necessitará de procedimentos invasivos e passará a ser excessivamente manuseado, sairá de um ambiente acolhedor aquático (intra-útero) e encontrará um lugar com nível sonoro alto, luzes e cheiros fortes, sentirá cansaço físico e mental, estresse, dor e desconforto e não terá quem o acalente ${ }^{(3)}$.

Sendo assim, as repercussões desses nascimentos ultrapassam tais questões afetando diretamente a família, que vivencia inúmeras dificuldades durante e após a hospitalização do neonato. A preocupação com a separação precoce e prolongada entre mãe-neonato e família, menor prevalência de aleitamento materno, maior demanda de atenção especial e de alto custo, dentre outros, promove importantes reflexões ${ }^{(4)}$.

Com o objetivo de oferecer um atendimento humanizado aos neonatos e suas famílias, o Ministério da Saúde lançou em 05/07/2000 a Norma de Atenção Humanizada ao Recém-Nascido Prematuro e/ou de Baixo Peso (Método Mãe Canguru) para melhor definir, apoiar e padronizar ações similares nas Unidades Neonatais integrantes do SUS. A adoção desta estratégia é considerada essencial na promoção de uma mudança institucional na busca da atenção à saúde centrada na humanização da assistência e no princípio de cidadania da família. Desse modo, o interesse pelo tema surgiu a partir da observação das dificuldades encontradas pela equipe de enfermagem que atua na Unidade de Cuidados Intermediários Neonatais - UCIN para a prática da assistência humanizada que contemple as necessidades biopsicossociais do neonato pré-termo e sua família. Além disso, a revisão de literatura apontou escassez de material acerca da temática, ressaltando a importância em se estudar o assunto.

Baseado no pressuposto de que a humanização da assistência ao neonato e sua família requer, sobretudo, uma mudança de postura na assistência prestada, este estudo versará sobre a seguinte questão: "como os cuidados de enfermagem estão sendo dispensados ao neonato pré-termo na unidade neonatal?".

Para tanto, a pesquisa teve como objetivo analisar a práxis cuidativa desenvolvida pela equipe de enfermagem de uma Unidade Neonatal ao neonato prétermo. A aquisição desses conhecimentos por parte dos pesquisadores, profissionais de saúde e comunidade em geral poderá auxiliar na adoção de uma atenção mais humanizada, eficaz e de qualidade ao neonato prétermo.

\section{MÉTODOS}

Trata-se de uma pesquisa do tipo descritivoexploratório, de natureza qualitativa, realizada nos meses de janeiro a junho de 2009. Esta modalidade de pesquisa tem por objetivo descrever as características de determinada população ou fenômeno, bem como proporcionar maior familiaridade com o problema com vista a torná-lo mais explícito ou construir hipóteses ${ }^{(5)}$.

O cenário escolhido foi a Unidade de Cuidados Intermediários Neonatais - UCIN de um hospital público 
no interior da Bahia destinada a receber neonatos prétermo ou que apresentam alguma patologia como, desconforto respiratório, asfixia perinatal, infecção neonatal e outras, cuja indicação não seja UTI neonatal. Essa unidade conta com médicos pediatras, enfermeiras, auxiliares e técnicos de enfermagem e fisioterapeutas. Além de servir de campo de prática e estágio acadêmico para os cursos de Enfermagem e Fisioterapia do Departamento de Saúde da Universidade Estadual do Sudoeste da Bahia.

As informantes foram 11 profissionais da Equipe de Enfermagem, que prestam cuidados direto ao neonato pré-termo escolhidos de forma aleatória e que concordaram em participar da mesma. Além disso, foi considerado o critério de saturação dos dados, uma vez que a quantidade de entrevistadas permitiu a reincidência das informações.

Para a coleta de dados, utilizou-se a entrevista semiestruturada, norteada por um formulário previamente elaborado. A primeira parte constou de questões fechadas com o intuito de realizar a caracterização dos sujeitos (idade, escolaridade, sexo, categoria profissional, carga horária e vínculo empregatício) e a segunda parte foi composta de questões abertas relacionadas com o objeto e os objetivos da pesquisa, quais sejam: - Como você cuida do neonato pré-termo? Qual a sua opinião a respeito da humanização da assistência aos neonatos pré-termo? Quais as dificuldades e facilidades encontradas para que seja desenvolvida uma assistência mais humanizada a esses neonatos?

As entrevistas foram realizadas na própria unidade em uma sala reservada, e duravam em média 30 minutos. As respostas foram registradas pela pesquisadora no momento da entrevista aproveitando-se a memória recente para que os dados fossem descritos com fidedignidade. Desse modo, a entrevista foi realizada face a face, de maneira metódica, propiciando as informações necessárias ${ }^{(6)}$.

Após aprovação do projeto de pesquisa pelo Comitê de Ética em Pesquisa - CEP da Universidade Estadual do Sudoeste da Bahia, protocolo $n^{\circ}$ 222/2009, em consonância com a resolução n 196/96 do Conselho Nacional de Saúde e, somente após todas as informantes estarem cientes dos seus direitos e concordarem em participar voluntariamente desta pesquisa, assinando o termo de consentimento, é que se procedeu a coleta de dados.

Рага assegurar o anonimato e sigilo das informantes, as mesmas foram identificadas de acordo com a ordem das entrevistas, ou seja, E1, E2, E3 e assim, sucessivamente.

Os dados coletados foram analisados de acordo com a análise de conteúdo temática de $\operatorname{Bardin}^{(7)}$. Inicialmente fez-se uma leitura flutuante dos depoimentos definindo, o corpus do trabalho. Em seguida, foi realizada uma leitura aprofundada dos depoimentos, a fim de estabelecer a análise. Selecionou-se elementos como palavras e frases dotadas de significados, sendo considerados como variáveis importantes ao processo de avaliação do sentido das opiniões, os quais se denominam unidades de registro. Posteriormente, as unidades de registro foram codificadas de acordo com a analogia dos significados e, finalmente, foram abstraídas as categorias $^{(7)}$.

\section{RESULTADOS E DISCUSSÃO}

Os 11 profissionais da enfermagem que participaram da pesquisa eram mulheres, sendo seis auxiliares de enfermagem, quatro técnicas e uma enfermeira. A predominância feminina na Enfermagem é compartilhada por muitas instituições de saúde e reproduz a característica histórica da profissão exercida quase que exclusivamente por mulheres, desde os seus primórdios.

Com relação à idade, a maioria das profissionais possui entre 54 e 62 anos. Os achados evidenciaram uma frequência maior de profissionais com idades avançadas, é relevante considerar este aspecto, pois o envelhecimento quase sempre está associado com uma diminuição na capacidade do indivíduo ao trabalho.

No que se refere ao grau de escolaridade, a maioria tem o ensino médio completo e a categoria profissional predominante foi a de Auxiliar de Enfermagem.

Os auxiliares de enfermagem representam o maior quantitativo na composição da força de trabalho em enfermagem, seguidos dos técnicos em enfermagem, ficando os enfermeiros na última posição, representando apenas uma pequena parcela de 13,64\%. Esse cenário caracteriza a divisão técnica do trabalho no interior da equipe de enfermagem que opera verticalmente, com base na redistribuição das tarefas entre o pessoal de diferentes níveis de qualificação, separando os 
momentos de concepção e gerenciamento (enfermeiros) daqueles de execução das atividades de cuidado (auxiliares e técnicos)(8), aspecto que se assemelha a realidade existente no cenário da pesquisa.

O vínculo empregatício predominante foi o Estatutário. Empiricamente pode-se constatar que o profissional que possui uma estabilidade no trabalho é mais satisfeito com o mesmo, o que favorece a motivação e a produtividade do profissional. Entretanto, as condições de trabalho a que são impostas, não contribuem para que as profissionais entrevistadas sejam motivadas, nem para que produzam adequadamente.

A maioria das profissionais trabalham durante 30 horas semanais o que se torna um fator positivo já que, atualmente, este período de atuação é considerado ideal para uma profissão que atua sob tensão, e com tarefas árduas, direcionadas para preservação da vida, que causam cansaço e estresse.

As categorias que emergiram do processo de análise foram: cuidados dispensados ao neonato pré-termo; diferença no cuidado entre o neonato pré-termo e os outros neonatos; concepção dos profissionais acerca da humanização na assistência ao neonato pré-termo e dificuldades e facilidades para humanizar a assistência ao neonato pré-termo.

\section{Cuidados dispensados ao neonato pré-termo}

Esta categoria revela as dimensões que os profissionais de enfermagem focam suas práticas assistenciais, quais sejam, nos aspectos biológicos, caracterizados pelos procedimentos técnicos e nos aspectos subjetivos, que envolvem o cuidar com afetividade.

Para a equipe de enfermagem, as práticas cuidativas pautadas nos procedimentos técnicos, envolvem o atendimento à condições biológicas, que são necessárias para o tratamento e prevenção de complicações, como pode ser observado a seguir:

...uso sempre luva para pegar neles (E11)

[...]cuidados higiênicos (E5)

[...]atenção ao manipulá-los (E6)[...]dar o leite nas horas certas (E4)

[...]dar a medicação no horário (E3)

[...]cuidados gerais de enfermagem como higiene $e$ medicação (E2)

\section{[...]curativo do coto umbilical(E9)}

[...] por em oxigênio sob hood e berço aquecido ou incubadora(E7)

[...]observo as extremidades, se tem desconforto respiratório (E8)

[...]pesar diariamente (E3)...

Grande parte das profissionais referiram o uso de técnicas de oxigenoterapia, alimentação, aquecimento, higienização, administração de medicamentos e exame físico para o cuidado ao neonato pré-termo. Chama a atenção a ausência de referencias à promoção da amamentação, como forma de cuidado, o que é preocupante, pois o alimento de escolha deveria ser o leite da própria mãe, que nas primeiras quatro semanas após o parto contém maior concentração de nutrientes e vitaminas, que aquele da mãe do neonato a termo, devendo ser ordenhado caso a criança ainda não consiga sugar ${ }^{(9)}$.

Poucos profissionais mencionam a utilização das relações afetivas com os prematuros como uma forma de cuidado, demonstrado nas seguintes unidades de análise:

\section{[...] tenho carinho com eles (E4)}

[...] a gente sempre conversa com eles, acarinha (E3)

[...] cuido como se fossem meus próprios filhos (E2)

[...] quando eles vão embora fico com lágrima nos olhos (E1)

[...] tem que dá também carinho e afeto (E5)...

Desta forma, percebe-se por meio da postura destes profissionais uma elevação na qualidade da assistência na medida em que, conseguem compreender que o tratamento do neonato pré-termo envolve muito mais do que apenas a utilização de procedimentos e técnicas e se preocupam com a abordagem holística desses pacientes, oferecendo conforto, carinho e atenção que lhe são necessários. Porém, não foi evidenciado nos achados a preocupação com o incentivo ao vínculo afetivo entre neonato e família que acaba sendo perdido ou enfraquecido durante a hospitalização da criança.

A enfermeira precisa dar à comunicação significado mais amplo pela interação, o que possibilita atitudes de sensibilidade, aceitação e empatia. Desta forma, há maior êxito nas ações de Enfermagem, como: atenção específica ao aconchego e toque terapêutico no 
neonato, cuidados de diminuição de luminosidade e ruídos na ambiência neonatal, acolhimento dos pais ${ }^{(10)}$.

\section{Diferença no cuidado entre o neonato pré-termo e os outros neonatos.}

Os neonatos que nascem antes do tempo merecem atenção diferenciada de médicos e psicólogos, entre outros profissionais de saúde, não apenas durante o período neonatal, mas, de preferência, até os cinco anos de idade, como forma de minimizar possíveis efeitos da prematuridade em seu desenvolvimento neuropsicomotor ${ }^{(11)}$.

Os profissionais que lidam com recém-nascidos hospitalizados devem ser dotados de conhecimentos a respeito da fisiologia e anatomia dos mesmos e suas diferenças entre neonatos que nasceram em períodos gestacionais distintos. Nesta categoria, destacam-se os principais aspectos em que as profissionais que atuam na Unidade Neonatal admitem diferir no cuidado prestado ao neonato pré-termo.

Os profissionais apontaram a apneia da prematuridade como uma patologia preocupante e que requer bastante cuidado:

\section{...tem que ter cuidado devido às apneias (E6)}

[...]tem que ter mais cuidado devido às crises de apneia (E4)

\section{[..]corre o risco de apneia (E2)}

[...] prematuro corre o risco de uma apneia (E10)[...]tem o risco de apneia (E5) [...]alguns tem apneia, se não ficar sempre observando ele pode morrer e agente nem vê (E7)...

A apneia é uma intercorrência comum em neonato pré-termo, que pode ser gerada de forma idiopática da prematuridade ou associada a patologias. Em neonato a termo, essa patologia é sempre preocupante e requer imediata avaliação diagnóstica. É uma característica das várias afecções que comprometem os neonatos. Essas intercorrências produzem apneia pela depressão direta do sistema de controle da respiração do sistema nervoso central (hipoglicemia, meningite, medicamentos, hemorragias, convulsões), distúrbios do fornecimento de oxigênio (choque, sepse, anemia), ou de defeitos de ventilação (pneumonia, hipertensão pulmonar persistente do neonato e fraqueza muscular) ${ }^{(12)}$.
A equipe de enfermagem concebe o neonato prétermo como um ser frágil, dotado de peculiaridades que o fazem merecedores de um cuidado e vigilância maior do que os demais recém-nascidos.

Tais explanações evidenciam a susceptibilidade do neonato pré-termo a afecções em sua saúde devido a indefesa que the é inerente e a imaturidade de diversos órgãos e sistemas que ainda estavam em processo de maturação quando suas mães deram à luz, como pode ser observado nas unidades de análise:

...eles são mais indefesos que os outros, não tem força nem pra chorar, apenas gemem(E9)

[...]necessitam de mais vigilância,eles são muito frágeis (E7)

[...]tem que saber manipular pra não fraturar nenhum osso (E6)

[...]por eles serem prematuros eles não tem as mesmas defesas que os outros têm(E5)

[...] gente sabe das deficiências deles (E4)

[...] tem que ter o maior cuidado(E2)

[...]por eles virem antes do tempo tem que ter o maior cuidado(E1)

[...]alguns órgãos, como os pulmões não estão maduros o suficiente(E11)

[...]o bebê prematuro não tem seu desenvolvimento completo, risco de vida maior que os outros (E8)

[...] ]ele não tem o reflexo bem desenvolvida, a pele que é muito fina, por falta de aquecimento pode perder temperatura(E10)[...]"

Como o neonato pré-termo não permaneceu no útero por tempo suficiente, todos os sistemas orgânicos podem ser imaturos, o que influencia a transição neonatal da vida intra-uterina para a extra-uterina e coloca o bebê sob risco de complicações. Sem o desenvolvimento completo, os sistemas dos órgãos não conseguem funcionar no nível necessário para manter a homeostase extra-uterina(13).

O neonato pré-termo é, portanto, considerado como de risco, necessitando de monitorização e cuidados especiais para sobreviver. É necessário que o sistema de saúde garanta o acesso desta população aos cuidados especializados e necessários para uma assistência de qualidade.

O neonato pré-termo, em razão da própria imaturidade cerebral, têm dificuldades de permanecer 
em estado de alerta, apresentando um tônus predominantemente extensor, reflexos orais ausentes ou incompletos, além de uma série de fatores que podem explicar as dificuldades de sucção e incoordenação com deglutição e respiração, retardando no ganho de peso e, consequentemente, prolongando a alta hospitalar ${ }^{(14)}$.

O cuidado com a alimentação é também diferente entre recém-nascidos de idade gestacional distintas, e aparece na fala dos profissionais que sabem a respeito de algumas particularidades do sistema gastrintestinal do prematuro:

... tem que ter o maior cuidado com a alimentação (E11)

[...] a alimentação deles tem que ser bem devagarzinho para não engasgar (E6)

[...] o estômago deles é menor que o dos outros, aí tem que dar menos leite pra eles (E5)

\section{[...]o leite tem que dá gota a gota senão engasga (E7)}

[...] ]ele tem também regurgitamento (E2)...

Desse modo, percebe-se que os profissionais entrevistados reconhecem a limitação da capacidade gástrica do neonato pré-termo, fazendo com que eles ofereçam a quantidade adequada de leite ao alimentar o neonato pré-termo. Além disso, o risco de que a criança aspire o alimento provocado pela cárdia e reflexos insuficientes, indicam que as de peso menor e mais imaturas necessitam de uma ingestão mais lenta e gradual do leite, o que também foi relatado por alguns informantes.

Diversos métodos podem ser empregados para promover a efetiva nutrição do neonato pré-termo, dentre eles a nutrição parenteral total (NTP) através de acesso venoso prolongado, ou alimentação enteral, que pode incluir aleitamento materno, alimentação contínua por cateter nasogástrico ou alimentação intermitente por tubo orogástrico (gavagem). A escolha por uma dessas técnicas deve ser feita com base na capacidade de deglutição e sucção do neonato(15).

Durante a realização das entrevistas pode-se observar que, na unidade neonatal onde foi desenvolvida esta pesquisa, é utilizada para os neonatos pré-termo a alimentação enteral por meio de copinhos ou seringas com leite artificial preparado pelo serviço de nutrição da instituição.

\section{Concepção dos profissionais acerca da humanização na assistência ao neonato pré-termo}

Nesta categoria destacam-se alguns aspectos que remetem a ideia de humanização a partir da perspectiva das profissionais. A análise do significado de humanização da assistência ao neonato pré-termo para as informantes deste estudo é um deles, revelada por meio do impacto do trabalho em equipe:

... a humanização tem que partir da equipe que deve se respeitar uns aos outros (E1)

[...] é um conjunto, eu e minhas colegas trabalhando juntas (E6)

[...] se comunicando em união (E2)

[...] se não humanizar com a outra dá muita confusão (E4)

[...] uma colega tem que confiar na outra (E7)...

Fica evidente nas falas das informantes que a humanização da assistência ao neonato pré-termo deve começar pelo respeito, união, comunicação e confiança entre os membros da equipe.

Peduzzi ${ }^{(16)}$ aborda dois conceitos referentes a ideia de equipe. A equipe como agrupamento de agentes, caracterizada pela fragmentação e a equipe como integração de trabalhos, caracterizada pela articulação consoante à proposta da integralidade das ações de saúde. Entende-se por articulação as situações de trabalho em que o agente elabora correlações e coloca em evidência as conexões entre as diversas intervenções executadas. Neste estudo, as informantes se reportaram a elementos imprescindíveis para a realização de um cuidado humanizado, partindo do respeito, união, comunicação e confiança entre os membros da equipe, possibilitando o desenvolvimento de ações de cuidado aos neonatos pré-termo de forma integral.

Portanto, para a efetivação do trabalho humanizado na unidade neonatal torna-se necessário a utilização da modalidade equipe integração na qual a articulação das ações e saberes entre os diversos profissionais seja capaz de produzir a assistência integral aos neonatos pré-termo, melhorando assim a qualidade da assistência prestada.

Destarte, "a humanização, muito mais do que um artifício, uma técnica, ou apenas uma intervenção significa estreitar relações interprofissionais, que possibilitem aos trabalhadores reconhecer a interdependência $e$ a complementaridade de suas ações, permitindo que o 
coração, junto à razão, se manifeste nas relações de trabalho do dia-a-dia"(17).

Sendo assim, para que o neonato pré-termo seja atendido de forma humanizada e, sobretudo integral, é necessário que a equipe de enfermagem trabalhe em sintonia entre si e com os demais integrantes da equipe de saúde, e para isso é necessário a adoção de instrumentos básicos como, a comunicação entre os profissionais, a valorização das ideias e opiniões dos trabalhadores e a socialização de ações que estabeleçam o bom convívio entre eles.

No entendimento dos profissionais entrevistados a humanização é importante por se tratar de um processo que não se resume apenas no atendimento técnico e mecânico ao neonato, mas que inclui um cuidado pautado em afetividade, carinho e atenção:

... é importante sim, os cuidados não se resumem apenas em trocar fralda e dar leite (E3)

[...] tem que dispor de mais tempo para eles, conversar com eles (E9)[...]fazer estimulação tátil (E10)

[...]é importante porque você dá mais afeto, acalenta, dar carinho (E11)

[...]porque fortalece o vínculo entre mãe e filho (E7)

[...]dá uma maior segurança para os bebês (E5)

[...] é importante porque eles necessitam de muita atenção (E8)...

As falas acima auxiliam na compreensão de que “humanizar não é uma técnica ou artifício, é um processo vivencial que permeia toda a atividade das pessoas que assistem o paciente, procurando realizar e oferecer o tratamento que ele merece como pessoa humana, dentro das circunstâncias peculiares que se encontra em cada momento no hospital" (18).

Em vista disso, pode-se admitir que a importância de humanizar a assistência aos neonatos prematuros, reside na perspectiva de que a adoção de tal modelo assistencial possa garantir que sejam atendidas suas necessidades como ser humano. Nenhum ser humano necessita somente de repouso, calor, nutrição, higiene e medicações, necessita também de alguém que the dê carinho, afeto, que the compreenda e the dê a devida atenção.

A Política Nacional de Humanização da Atenção e Gestão do SUS tem como um dos seus objetivos, efetivar os princípios do SUS, dentre eles a integralidade da assistência e como um dos focos a mudança nos modelos de atenção, garantindo o atendimento das necessidades dos cidadãos ${ }^{(19)}$.

Considerando que a humanização da assistência visa, sobretudo garantir a integralidade da atenção em saúde, não se pode esquecer que o desenvolvimento dos neonatos pré-termo é determinado por um misto de necessidades que perpassam tanto a área biológica como afetiva. Assim sendo, o pré-termo necessita ter seu desenvolvimento afetivo preservado mesmo estando separado dos seus pais em decorrência da hospitalização.

Atualmente se reconhece a importância da equipe de saúde promover a ligação afetiva entre o neonato pré-termo e seus pais, no intuito de diminuir os efeitos negativos da internação neonatal para ambos e aumentar o senso de responsabilização dos pais com relação à recuperação de seu filho. Tal ligação também foi enfatizada pelos profissionais entrevistados como um dos pontos positivos em se humanizar a assistência.

A equipe de saúde pode favorecer a formação desses laços afetivos utilizando alguns recursos como: facilitar os contatos iniciais dos pais com neonato, antes mesmo que ele seja admitido na unidade neonatal; dando informações sobre para onde o neonato será encaminhado, os cuidados que ele receberá e o direito de visitá-lo sempre que desejarem; incentivá-los a tocar e conversar com o neonato; explicar sobre os equipamentos e tratamentos que o neonato está utilizando; não dificultar a sua entrada na unidade; tornar o ambiente acolhedor; permitir que participem dos cuidados com o neonato sempre que possível; escutar com atenção o que eles têm a dizer, esclarecendo dúvidas e aliviando preocupações e iniciar o Método Mãe Canguru assim que possível(20).

As publicações sobre as vantagens Método Mãe Canguru, modelo de assistência neonatal voltado para o cuidado humanizado abordam, principalmente: "o favorecimento da formação do vínculo mãe-bebê, a proximidade e o toque promovidos entre os pais e os recém-nascidos e o desenvolvimento do senso de competência por parte das mães participantes do método"(21).

É importante saber que as profissionais entrevistadas reconhecem a importância da adoção de uma assistência humanizada como um valor para a conquista de uma melhor qualidade de atendimento à 
saúde ao recém-nascido pré-termo, pautada em princípios e valores como ética, solidariedade, vínculo, responsabilização e, sobretudo, no respeito à vida humana, imprescindíveis para a práxis cuidativa da equipe de enfermagem que atua em uma unidade de cuidados a neonatos.

A humanização pode ser considerada uma forma de assistência que valoriza a qualidade do cuidado técnico, levando em conta o reconhecimento dos direitos do cliente, de sua subjetividade e valores culturais, incluindo a valorização do profissional e do diálogo intra e inter equipes ${ }^{(22)}$.

\section{Dificuldades e facilidades para humanizar a assistência ao neonato pré-termo}

Na perspectiva dos participantes, a organização do trabalho e da assistência à saúde no ambiente da unidade neonatal onde foi realizada esta pesquisa não deixa dúvidas de que a estrutura física, tecnológica e humana não garante condições para que seja oferecida uma assistência humanizada aos neonatos, o que pode ser comprovado pelas expressões:

... temos carência de funcionários, pediatras de plantão (E8)

[...]à noite e fim de semana não tem enfermeiro aqui (E7)

[...] a dificuldade aqui é a falta de funcionários (E5)

[...]à noite só fica um aqui pra cuidas de tantos bebês (E3)

[...] se tivesse mais funcionário daria pra dá mais atenção à eles (E2)

[...]ás vezes não dá tempo de dá carinho, atenção porque o cuidado é feito muito rápido, agente fica só aqui (E1)

\section{[...] estou aqui sozinha com 14 crianças (E4)}

[...]como vou prestar um cuidado humanizado(E6)

[...] agente acaba só dando os cuidados básicos mesmo, como banho e alimentação(E9) [...] a estrutura física, não tem como as mães ficarem aqui (E11)

[...] os prematuros extremos necessitam de uma monitorizarão maior (E10)...

Tendo como pressuposto de que a falta de condições de trabalho e a humanização da assistência não conseguem caminhar juntas, pode-se perceber que um dos principais empecilhos à adoção desse modelo de assistência, na perspectiva dos sujeitos dessa pesquisa é a carência de pessoal para atender à demanda de neonatos da unidade.
O Departamento de Neonatologia da Sociedade Brasileira de Pediatria - SBP publicou um Documento Científico no ano de 2004 onde consta a infraestrutura necessária às instituições hospitalares para atendimento integral ao recém-nascido ${ }^{(19)}$.

Com relação aos Recursos Humanos para a Unidade de Cuidados Intermediários Neonatais - UCIN, classificação em que se encontra a unidade estudada, é recomendado um pediatra com certificado de Especialista em Pediatria com área de atuação em Neonatologia que trabalhe em regime diarista exclusivo para 15 leitos ou fração, um pediatra com título de Especialista em Pediatria plantonista para 15 leitos ou fração por turno de trabalho, um enfermeiro coordenador, um enfermeiro exclusivo da unidade para 15 leitos ou fração para cada turno, um técnico ou auxiliar de enfermagem para cinco leitos ou fração por turno, um funcionário exclusivo pela limpeza do serviço ${ }^{(23)}$.

No entanto, a unidade neonatal onde foi realizada esta pesquisa não atende as recomendações da SBP por possuir somente um enfermeiro coordenador em regime diarista, não possuir um enfermeiro exclusivo da unidade para cada turno e ausência de pediatra plantonista. Além disso, excede o número mínimo de leitos para cada auxiliar ou técnico de enfermagem, pois é frequente trabalhar apenas um profissional para cuidar de até 14 crianças.

A sobrecarga de trabalho dos profissionais repercute de forma devastadora na qualidade da assistência, uma vez que o tempo destinado a cuidar de cada neonato de forma individualizada fica bastante reduzido, causando riscos a sua saúde e privação de seus direitos como cidadã. Além disso, o cuidado humanizado está inteiramente ligado ao profissional que o executa, seu estado psicológico e físico, podendo ser o cansaço um fator desfavorável a sua prática.

É preciso destacar que as dificuldades relatadas pelos profissionais repercutem não só no seu fazer profissional, mas, também tem um potencial de vir a causar danos em sua saúde física e mental, devido à sobrecarga de trabalho que lhe é imposta. O profissional não consegue agir humanamente, se ele não tem condições dignas de trabalho, não é valorizado e nem respeitado como merece.

Outro obstáculo à humanização identificado neste estudo foi a falta de recursos tecnológicos para prestar 
uma assistência qualificada. Os equipamentos necessários para à assistência integral aos neonatos prétermo, também são essenciais para a qualificação e humanização do cuidado, uma vez que a falta dos mesmos não garante que a assistência seja completa e que responda verdadeiramente as suas necessidades.

A estrutura física deficiente também foi identificada pelos entrevistados como mais um empecilho à humanização da assistência, pois esta não oferece condições para que as mães fiquem o tempo suficiente com seus filhos, e desta forma, não contribui para a formação do vínculo afetivo entre eles.

Como facilidades para humanizar o cuidado ao neonato pré-termo, os profissionais de enfermagem destacaram:

... a compreensão e amor dos funcionários daqui (E6)

[...] os pediatras são muito responsáveis (E2)

[...] trabalhamos bem em equipe (E1)

[...] os funcionários daqui são bem treinados e quase não faltam ao serviço (E11)

[...] os bebês são seres humanos pequenos e fáceis de manusear(E9)...

Em meio a tantas dificuldades, a humanização da assistência ainda pode ser vista como algo possível de ser realizado ao se levar em conta os aspectos relatados pelas entrevistadas, que dizem respeito a suas relações com o trabalho, como a habilidade em lidar com neonatos, responsabilidade, amor e compreensão para lidar com as dificuldades e o trabalho em equipe.

Quando o profissional é habilitado para atuar em um determinado setor e assistir uma determinada clientela, o desenvolvimento de um trabalho humanizado torna-se mais fácil, já que suas ações serão realizadas com prazer e dedicação, sem se deixar influenciar pelo tecnicismo, dando o melhor de si para o outro.

É preciso resgatar valores humanísticos perdidos pela cultura organizacional das instituições de saúde, que estão voltados para a mecanização do trabalho, do tecnicismo e da patologia, perdendo de vista vivências importantes para a realização do cuidado a saúde humanizado(24).

O trabalho em equipe, quando realizado de forma interdisciplinar e não apenas multidisciplinar torna a humanização do cuidado um projeto não muito distante da realidade do serviço, uma vez que trabalhando nesta perspectiva, os saberes e decisões são compartilhados, tornando-se possível a construção de projetos terapêuticos singulares, no qual cada membro da equipe sabe quais são as suas responsabilidades na assistência ao paciente. Tudo isso resulta na qualificação da assistência e melhoria da situação de saúde dos pacientes, igualmente humanizando o cuidado.

\section{CONSIDERAÇÕES FINAIS}

A partir da análise dos dados constatamos que a práxis cuidativa desenvolvida pelas profissionais é predominantemente tecnicista, com o uso de procedimentos e técnicas que visam controlar e manter as funções fisiológicas e o conforto físico dos neonatos. Os cuidados afetivos, que envolvem relacionamento interpessoal foram pouco destacados. Uma consideração relevante a ser feita é que não foram mencionados como forma de cuidado a promoção do aleitamento materno, nem o incentivo ao vínculo entre neonato e família, tão importantes para o desenvolvimento saudável dos neonatos pré-termo.

Foi identificado ainda, que os profissionais conseguem compreender algumas particularidades do neonato pré-termo, o que faz diferença no cuidado prestado, a exemplo da apneia, a alimentação diferenciada, fragilidade da pele, ossos e sistema corporal como o imunológico, respiratório, gastrintestinal e nervoso.

Outro aspecto revelado nos resultados foi que os profissionais conhecem a importância em se humanizar a assistência, por se tratar de um processo que garante a melhoria da qualidade da assistência e, consequentemente, da qualidade de vida dos neonatos. No entanto, eles não trabalham nesta perspectiva quando caracterizaram suas práticas cuidativas.

A carência de recursos humanos e físicos dificulta o desenvolvimento da assistência humanizada, uma vez que não oferece condições para que os profissionais possam cuidar do neonato pré-termo com qualidade. Não obstante, foi perceptível também a existência de algumas condições facilitadoras para a humanização da assistência como a habilidade e gosto pelo trabalho e o fato de estarmos falando de uma equipe que trabalha de forma harmoniosa.

Sugere-se que a instituição hospitalar reorganize o quadro de pessoal a fim de adequá-lo as necessidades da Unidade Neonatal, e que ofereça oportunidade para que 
os profissionais adquiram mais conhecimentos por intermédio da capacitação e educação continuada no próprio serviço, que abordem a importância e manejo do aleitamento materno, Método Canguru e a inserção da família como participante ativa do tratamento do RN internado.

Torna-se necessário, também, a realização de mudanças na estrutura física da unidade para que o ambiente torne-se adequado as ações de humanização conforme normas do Ministério da Saúde.

\section{REFERÊNCIAS}

1. Organización Mundial de la Salud (OMS). Departamento de Salud Reproductiva e Investigaciones Conexas. Método Madre Canguro: guia práctica [Internet]. Ginebra; 2003. [cited 2010 mar 23]; Available from: http://www.federacion-

matronas.org/ipn/documentos/i/3751/144/metodo-madre-canguroguia-practica.

2. Rabelo MZS, Chaves EMC, Cardoso MVLML, Sherlock MSM. Sentimentos e expectativas das mães na alta hospitalar do recémnascido prematuro. Acta Paul Enferm. [Internet]. 2007 [cited 2010 mar 23];20(3):333-7. Available from:

http://dx.doi.org/10.1590/S0103-21002007000300015.

3. Secretaria de Políticas de Saúde, Área de Saúde da Criança. Atenção humanizada ao recém-nascido de baixo peso: método mãe canguru, manual do curso. Brasília (Brasil): Ministério da Saúde, 2002.196p.

4. Silva LJ, Silva LR, Christoffel MM. Tecnologia e humanização na Unidade de Terapia Intensiva Neonatal: reflexões no contexto do processo saúde-doença. Rev. Esc. Enferm. USP [Internet].2009 [cited 2010 mar 24];43(3):684-689.Available from: http://www.scielo.br/pdf/reeusp/v43n3/a26v43n3.pdf.

5. Gil AC. Como elaborar projetos de pesquisa. São Paulo: Atlas; 2002.

6. Marconi, MA,Lakatos, E M. Metodologia Científica. 4st ed. São Paulo: Atlas; 2004

7. Bardin, L. Análise de Conteúdo.Tradução de Luis Antero Reto e Augusto Pinheiro. Lisboa: Edições 70, 2009.

8. Felli VEA, Peduzzi M. O Trabalho gerencial em enfermagem. In: Gerenciamento em enfermagem.Coord. Kurcgant P. Rio de janeiro: Guanabara Koogan; 2005

9. Nascimento, MBR,Issler, H. Aleitamento materno em prematuros: manejo clínico hospitalar. Jornal de Pediatria [Internet]. 2004 [cited 2010 mar 25];80(5):163-162.Available from:

http://www.ibfan.org.br/documentos/.

10. Farias LM, Cardoso MVLML, Oliveira MMC, Melo GM, Almeida LS. Comunicação proxêmica entre a equipe de enfermagem e o recémnascido na unidade neonatal. Rev. Rene. [Internet]. 2010 [cited 2010 abr 08]; 11(2):37-43. Available from:

http://www.revistarene.ufc.br/11.2/a04v11n2.pdf.

11. Belik J, Tessler, R. Prematuro: um ser especial [Internet].

Available from:

http://amamentacao.com/a_artigos.asp?id=x\&id_artigo=1351\&id_su bcategoria $=5$.

12. Berhman RE, KliegmanRM, Jenson, HB. Nelson, Tratado de

Pediatria. 17st ed. Rio de Janeiro: Elsevier; 2005

13. Ricci SS. Enfermagem Materno-Neonatal e Saúde da Mulher. Rio de Janeiro: Guanabara Koogan; 2008.

14. Andrade ISN, Guedes, ZCF. Sucção do recém-nascido prematuro: comparação do método Mãe-Canguru com os cuidados tradicionais. Rev. Bras. Saúde Matern. Infant. [Internet]. 2005 [cited 2010 abr 29];5(1):61-69. Available from:

http://www.scielo.br/pdf/rbsmi/v5n1/a08v05n1.pdf.

15. Schmitz EM et al. A enfermagem em pediatria e puericultura. São Paulo: Atheneu; 2000
Feitas estas considerações, consideramos este estudo de grande relevância vez que os conhecimentos adquiridos podem servir de base para o início de mudanças institucionais com o escopo de garantir uma assistência mais humana e de qualidade aos neonatos pré-termo e suas famílias, assim como servir de substrato para a realização de pesquisas de outros acadêmicos e profissionais interessados por temas desse âmbito.

16. Peduzzi M. Equipe multiprofissional de saúde: conceito e tipologia. Rev. Saúde Públ [Internet]. 2001 [cited 2010 abr 10];35(1):103-9.Available from:

http://www.fnepas.org.br/pdf/cobem07/peduzzi cobem 07.pdf. 17- Backes DS, Filho WDL, Lunardi VL. O processo de humanização do ambiente hospitalar centrado no trabalhador. Rev. esc. enferm. USP. [Internet]2006 [cited $2010 \mathrm{abr}$ 26]; 40(2):221-7.Available from: www.ee.usp.br/reeusp/upload/pdf/242.pdf

18. Reichert APS, Lins RNP, Collet N. Humanização do Cuidado da UTI Neonatal. Rev. Eletr. Enf. [Internet]. 2007 [cited 2010 abr 29] ;09(1): 200-213. Available from:

http://www.fen.ufg.br/revista/v9/n1/v9n1a16.htm.

19. Secretaria de Atenção à Saúde, Ministério da

Saúde.HumanizaSUS: Documento base para gestores e trabalhadores do SUS. 4. ed. Brasília (Brasil): Ministério da Saúde; 2008.

20. Cruvinel FG, Pauletti CM. Formas de atendimento humanizado ao recém nascido pré-termo ou de baixo peso na unidade de terapia intensiva neonatal: uma revisão. Cadernos de Pós-Graduação em Distúrbios do Desenvolvimento [Internet]. 2009 [cited 2010 mai 29]; 9(1):102-125. Available from:

http://www.mackenzie.br/fileadmin/Graduacao/CCBS/PosGraduacao/Docs/Cadernos/Caderno vol 8/2009.2Artigo 7 FORMA S DE ATENDIMENTO HUMANIZADO AO RECEM NASCIDO PRETERMO_OU DE_BAIXO_PESO_NA_UNIDADE_DE_TERAPIA_INTENSI VA_NEONATAL_UMA_REVISAO.pdf.

21. Costa R, Monticelli M. Método Mãe-Canguru Acta Paul Enferm. [Internet]. 2005 [cited 2010 abr 29];18(4):427-33. Available from: http://www.scielo.br/pdf/ape/v18n4/a12v18n4.pdf.

22. Deslandes SF. Análise do discurso oficial sobre a humanização da assistência hospitalar. Ciênc. saúde colet [Internet].2004 [cited 2010 mai 1]; 9(1):7-14. Available from:

http://www.scielo.br/pdf/csc/v9n1/19819.pdf.

23. Almeida MFB, Rego MAS, Costa HPF. Infra-estrutura para atendimento integral ao recém-nascido. Documento Científico do Departamento de Neonatologia da Sociedade Brasileira de Pediatria [Internet] 2004. Available from:

http://www.sbp.com.br/show_item2.cfm?id_categoria=21\&id_detal he $=1636 \&$ tipo detalhe $=$ s.

24. Rios IC. Humanização: a Essência da Ação Técnica e Ética nas Práticas de Saúde. Rev. bras. educ. med. [Internet]. 2009 [cited 2010 mai 29]; 33(2):253-261. Available from:

http://www.scielo.br/pdf/rbem/v33n2/13.pdf.

Artigo recebido em 13/03/2011.

Aprovado para publicação em 28/03/2012.

Artigo publicado em 30/09/2012. 